\title{
BEHAVIOUR AND TRANSMISSION OF SUPERNUMERARY CHROMOSOMES IN AEGILOPS SPELTOIDES
}

\author{
DAN MENDELSON and DANIEL ZOHARY \\ Laboratory of Genetics, The Hebrew University, Jerusalem, Israel
}

Received 14.i.72

\section{INTRODUCTION}

Aegilops speltoides ( $=$ Triticum speltoides) is a wild diploid $(2 n=14)$ wheat growing in the East Mediterranean Basin. It is also the supposed donor of the second genome to tetraploid wheats (Triticum turgidum group). Recently several populations of this wild wheat were found to contain supernumerary chromosomes (in Israel, see Simchen et al., 1971, and in southern Turkey, Zohary, unpublished).

This paper deals with the stability and mode of transmission of the accessory chromosomes in Ae. speltoides. The somatic stability of these chromosomes was examined in different chromosome types and in various branches and organs of the same individuals. In representative plants (with $\mathrm{B}$ chromosomes ranging from one to six) the behaviour of the supernumeraries was traced in meiosis and in the development of the male gametophyte. Such plants were also used in a crossing programme aimed at the elucidation of the mode of transmission of these chromosomes.

\section{Materials and methods}

Chromosomes were counted after squashing with 2 per cent. acetocarmine. The material was fixed in $3: 1$ absolute alcohol : glacial acetic acid and stored in 70 per cent. alcohol. Root-tips hypocotyls and apices were pre-treated with saturated water solution of paradichlorobenzen. For the study of meiosis and the first division in the pollen grain, fixed anthers were pre-stained for 10-14 hours in alcoholic carmine (Snow, 1963). Anthers used for the study of the second division in the male gametophyte were not fixed; pollen grains were squeezed out from the live anthers and immediately squashed in 2 per cent. aceto-carmine.

The chromosomal constitution of progeny (transmission tests) was determined in the seedling stage. Kernels were germinated approximately 4 weeks after ripening. To ensure full germination, 300 p.p.m. giberellic acid was added to the water. The seedlings were fixed when the length of the coleoptile reached $15 \mathrm{~mm}$. The hypocotyl tissues at this stage contained numerous dividing cells (see fig. 1). They were macerated in 9:12 per cent. aceto-carmine: $1 \mathrm{~N} \mathrm{HCl}$ for 30 seconds and then squashed with 2 per cent. aceto-carmine.

Since Ae. speltoides is self-compatible (see Zohary and Imber, 1963), crosses were performed after emasculation (1-2 days before anthesis). Florets were hand-pollinated.

Pollen fertility was determined by dissecting mature anthers soaked in 4 per cent. aceto-carmine and scoring $c .500$ pollen grains per plant. Grains were considered normal when they appeared rounded and well stained. 
Seed fertility was determined by examination of the two lower florets in the spikelet. A floret was regarded fertile if a well-developed kernel was found in it. In each plant a sample of 100 florets (i.e. 50 spikelets) was employed.

\section{VARIATION WITHIN PLANTS}

Three families of sibs served for this survey. Two families (\#145 and \#168) were derived from $2 n=14+2 B$ parents and a third (\#1601) was

TABle 1

Occurrence of supernumerary chromosomes in different organs in Aegilops speltoides. Chromosomal constitution of vegetative tillers, flowering spikes and the seedlings' radicle-in the same plant

Chromosomal constitution

\begin{tabular}{|c|c|c|c|}
\hline Plant no. & Tillers & Spikes & Radicle \\
\hline $145-1$ & $14+6 \mathrm{~B}(2)$ & $14+6 B(5)$ & 14 \\
\hline $145-10$ & $14+4 \mathrm{~B}(1)$ & $14+4 \mathrm{~B}(2)$ & 14 \\
\hline $145-11$ & $14+2 B(1)$ & $14+2 B(3)$ & 14 \\
\hline $145-14$ & $14+1 \mathrm{~B}(1)$ & $14+1 \mathrm{~B}(2)$ & 14 \\
\hline $145-23$ & $14+4 \mathrm{~B}(1)$ & $14+4 \mathrm{~B}(2)$ & 14 \\
\hline $145-25$ & $14+4 B(1)$ & $14+4 \mathrm{~B}(3)$ & 14 \\
\hline $145-28$ & $14+3 \mathrm{~B}(1)$ & $14+3 \mathrm{~B}(2)$ & 14 \\
\hline $145-29$ & $14+5 B(1)$ & $14+5 B(2)$ & 14 \\
\hline $145-37$ & $14+5 B(1)$ & $14+5 B(2)$ & 14 \\
\hline $145-42$ & $14+6 \mathrm{~B}(1)$ & $14+6 \mathrm{~B}(6)$ & 14 \\
\hline $145-43$ & $14+4 \mathrm{~B}(1)$ & $14+4 \mathrm{~B}(2)$ & 14 \\
\hline $145-44$ & $14+6 \mathrm{~B}(1)$ & $14+6 \mathrm{~B}(4)$ & 14 \\
\hline $145-46$ & $14+3 \mathrm{~B}(1)$ & $14+3 B(3)$ & 14 \\
\hline $145-47$ & $14+4 \mathrm{~B}(1)$ & $14+4 \mathrm{~B}(2)$ & 14 \\
\hline $168-1$ & $14+3 \mathrm{~B}(1)$ & $14+3 \mathrm{~B}(1)$ & 14 \\
\hline $168-2$ & $14+3 \mathrm{~B}(1)$ & $14+3 \mathrm{~B}(2)$ & 14 \\
\hline $168-3$ & $14+1 \mathrm{~B}(2)$ & $14+1 \mathrm{~B}(2)$ & 14 \\
\hline $168-33$ & $14+1 \mathrm{~B}(1)$ & $14+1 \mathrm{~B}(3)$ & 14 \\
\hline $168-43-1$ & $14+3 \mathrm{~B}(1)$ & $14+3 \mathrm{~B}(2)$ & 14 \\
\hline $168-48$ & $14+1 \mathrm{~B}(1)$ & $14+1 \mathrm{~B}(3)$ & 14 \\
\hline $1601-5$ & $14+1 \mathrm{~B}(1)$ & $14+1 B(5)$ & 14 \\
\hline $1601-8$ & $14+1 \mathrm{~B}(1)$ & $14+1 \mathrm{~B}(3)$ & 14 \\
\hline $1601-13$ & $14+1 \mathrm{~B}(1)$ & $14+1 \mathrm{~B}(3)$ & 14 \\
\hline $1601-14$ & $14+3 \mathrm{~B}(1)$ & $14+3 \mathrm{~B}(2)$ & 14 \\
\hline $1601-34$ & $14+3 \mathrm{~B}(1)$ & $14+3 \mathrm{~B}(2)$ & 14 \\
\hline $1601-38$ & $14+3 \mathrm{~B}(1)$ & $14+3 \mathrm{~B}(1)$ & 14 \\
\hline $1601-41$ & $14+1 \mathrm{~B}(2)$ & $14+1 \mathrm{~B}(1)$ & 14 \\
\hline $1601-47$ & $14+1 \mathrm{~B}(1)$ & $14+1 \mathrm{~B}(4)$ & 14 \\
\hline
\end{tabular}

Note: Numbers in brackets indicate the number of tillers and spikes examined in each plant.

obtained from a $2 n=14+3 \mathrm{~B}$ plant. In each family chromosomes were counted in several sibs-and in different organs within each individual: $(a)$ in the growing point of the vegetative tillers, $(b)$ in microsporocytes of the flowering spikes, $(c)$ in root-tips of the germinating seedlings and $(d)$ in adventitons roots.

In all plants the number of supernumerary chromosomes was constant in different aerial parts within the same individual (table 1). Surprisingly, in view of this pronounced stability in the aerial organs, B chromosomes were 
totally absent in the roots. In 75 plants we were able to check chromosome numbers both in the tip of the radicle and in at least one spike or tiller. All aerial organs contained one or more supernumeraries; the roots had none. Furthermore, this total elimination of supernumeraries in roots was observed already early in development, when the germinating radicle was only 4-8 mm. long.

Additional information on this phenomenon was obtained upon examination of 38 adventive roots, developing on the internodes of secondary and tertiary tillers (table 2). Here, too, supernumeraries were totally absent. The apical meristem of all adventive roots contained only 14 regular chromosomes.

TABLE 2

Occurrence of supernumerary chromosomes in different organs in Aegilops speltoides. Chromosomal constitution of tillers, flowering spikes and adventive roots which developed on their lower internodes

Chromosomal constitution

\begin{tabular}{ccc} 
& \multicolumn{2}{c}{ Chromosomal constitution } \\
Plant no. & $\begin{array}{c}\text { Tillers and } \\
\text { flowering spikes }\end{array}$ & Adventive roots \\
$145-12$ & $14+3 \mathrm{~B}(2)$ & $14(3)$ \\
$145-18$ & $14+3 \mathrm{~B}(2)$ & $14(3)$ \\
$145-29$ & $14+5 \mathrm{~B}(3)$ & $14(2)$ \\
$145-35$ & $14+3 \mathrm{~B}(2)$ & $14(2)$ \\
$168-7$ & $14+3 \mathrm{~B}(2)$ & $14(3)$ \\
$168-13$ & $14+3 \mathrm{~B}(2)$ & $14(5)$ \\
$168-14$ & $14+3 \mathrm{~B}(1)$ & $14(1)$ \\
$168-48$ & $14+1 \mathrm{~B}(4)$ & $14(2)$ \\
$1601-6$ & $14+3 \mathrm{~B}(2)$ & $14(1)$ \\
$1601-7$ & $14+3 \mathrm{~B}(2)$ & $14(5)$ \\
$1601-32$ & $14+3 \mathrm{~B}(2)$ & $14(4)$ \\
$1601-41$ & $14+1 \mathrm{~B}(3)$ & $14(2)$ \\
$1601-43$ & $14+3 \mathrm{~B}(1)$ & $14(1)$ \\
$1601-44$ & $14+3 \mathrm{~B}(2)$ & $14(3)$ \\
$1601-47$ & $14+1 \mathrm{~B}(6)$ & $14(1)$
\end{tabular}

Note: Numbers in brackets indicate the number of tillers, spikes and adventive roots examined in each plant.

\section{Segregation in meiosis}

The behaviour of the $\mathrm{B}$ chromosomes in microsporogenesis was studied in representative individuals. The results obtained are set in table 3.

\section{(i) Plants with a single supernumerary chromosome}

In the majority of the PMCs (80-85 per cent.) in metaphase I, the single B chromosome appears as an univalent-outside the equatorial plate. Anaphase I and telophase I are characterised by frequent lagging of the single supernumerary (fig. 4) and such laggards often divide precociously. Laggards are usually not included in the daughter nuclei and appear, at the end of meiosis, as micronuclei.

In the minority of the microsporocytes (15-20 per cent.), the single B chromosome migrates effectively towards one of the two poles to be included in the daughter nucleus. In such cases the second meiotic division appears Y 2 


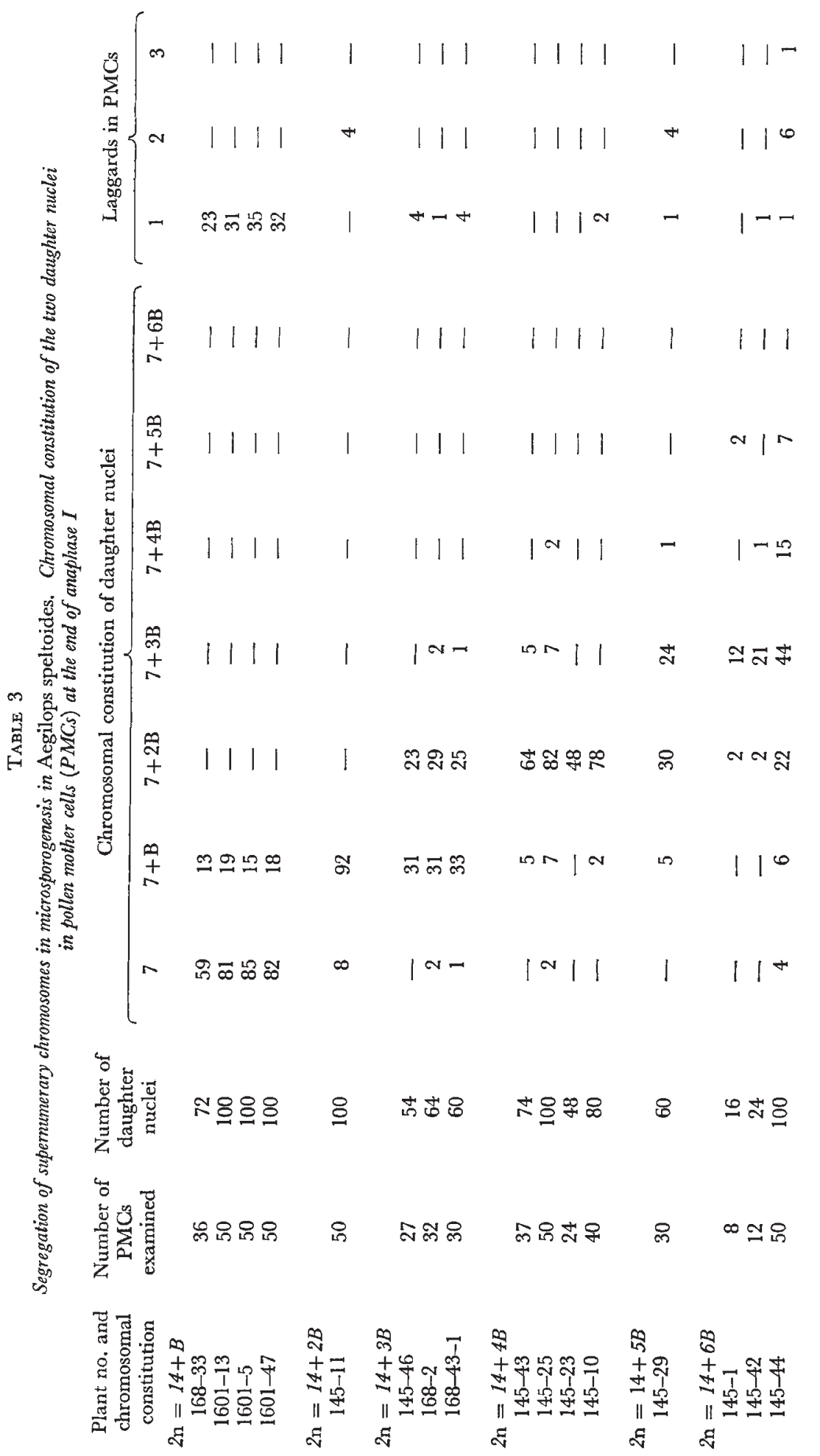


regular, and two out of the four spores of the consequent tetrad contain $n=7+\mathrm{B}$ chromosomes.

Tetrad analysis was performed in three plants (table 4). In 80-82 per cent. of the tetrads we encountered at least one micronucleus (and usually

TABLE 4

Loss of supernumerary chromosomes in microsporogenesis in Aegilops speltoides. Formation of micronuclei in tetrads produced by $2 \mathrm{n}=14+B$ plants

\begin{tabular}{|c|c|c|c|c|}
\hline Plant no. & $\begin{array}{l}\text { Number of } \\
\text { tetrads } \\
\text { examined }\end{array}$ & $\begin{array}{c}\text { Tetrads } \\
\text { with } 0 \\
\text { micronuclei }\end{array}$ & $\begin{array}{c}\text { Tetrads } \\
\text { with } 1 \\
\text { micronucleus }\end{array}$ & $\begin{array}{c}\text { Tetrads } \\
\text { with } 2 \\
\text { micronuclei }\end{array}$ \\
\hline $1601-13$ & 50 & 10 & 7 & 33 \\
\hline $1601-47$ & 50 & 8 & 14 & 28 \\
\hline $168-33$ & 35 & 8 & 8 & 19 \\
\hline Total & 135 & 26 & 29 & 80 \\
\hline
\end{tabular}

two microneclei). These results corroborate the observations made in metaphase I and anaphase I and indicate that in $2 n=14+B$ plants appreciable loss of $B$ chromosomes occurs during the first meiotic division.

\section{(ii) Plants with two supernumerary chromosomes}

Meiosis is characterised here by frequent pairing between the two B's. In approximately half of the metaphase I cells the two supernumeraries form a bivalent (usually a rod bivalent, but occasionally also a ring bivalent). In such cells segregation is normal. But even when the two B's stay apart, they usually face each other on the two opposing sides of the equatorial plate. Subsequently they separate in anaphase $I$ in a more or less regular way. Laggards are very seldom observed in the $2 n=14+2 \mathrm{~B}$ plant (table 3 ). At the end of meiosis anthers contain normal-looking tetrads, consisting of $n=7+\mathrm{B}$ spores.

\section{(iii) Plants with three supernumerary chromosomes}

These are characterised by variable configurations in metaphase I. In some cells all three supernumeraries appear as univalents. In others a bivalent and a univalent are present. In still other cells trivalents are formed (fig. 2). Laggards in anaphase I are relatively rare, but unipolar distribution was occasionally detected. Consequently, the resultant microspores may contain not only one or two B's but even three supernumeraries.

\section{(iv) Plants with numerous (four to six) supernumeraries}

In metaphase I the supernumeraries in these plants appear either as univalents or associated in various combinations-from bivalents up to hexavalents (fig. 3). There is surprisingly little lagging in anaphase $I$ and in the majority of cells segregation is more or less regular. In occasional cells we encountered unipolar distribution of supernumeraries, i.e. the migration of all (or most) of the supernumeraries in the meiocyte toward one pole. 
Such distribution leads to the formation of haploid spores, containing the number of B's previously found in the diploid sporocyte.

\section{NoN-Disjunction in the male Gametophyte}

The behaviour of $\mathrm{B}$ chromosomes in pollen grains was studied in plants containing one to four supernumerary chromosomes. The mode of division of the supernumeraries was first traced in the first division of the pollen grain. But dividing pollen grains at the critical anaphase stage were very rare. Consequently quantitative information was obtained from the pollen grains undergoing their second gametophytic division. In Aegilops speltoides, as in Dactylis glomerata (Puteyevsky and Zohary, 1970), the chromosomal constitution of the generative nucleus could be easily assessed in the metaphase stage of the second pollen grain division. In other words, the constitution of the dividing generative nucleus indicated to us what happened during the first division of the pollen grain. The results are set up in table 5 and can be summarised as follows:

TABLE 5

Chromosome constitution of the generative nucleus in pollen grains in various Ae. speltoides plants

\begin{tabular}{|c|c|c|c|c|c|c|c|}
\hline \multirow{2}{*}{$\begin{array}{l}\text { Plant no. } \\
\text { and diploid } \\
\text { chromosomal } \\
\text { constitution }\end{array}$} & \multirow{2}{*}{$\begin{array}{l}\text { Number of } \\
\text { pollen } \\
\text { grains } \\
\text { examined }\end{array}$} & \multicolumn{6}{|c|}{ Chromosomes in the generative nucleus } \\
\hline & & $n=7$ & $n=7+\mathrm{B}$ & $n=7+2 \mathrm{~B}$ & $n=7+3 \mathrm{~B}$ & $n=7+4 \mathrm{~B}$ & $n=7+8 \mathrm{~B}$ \\
\hline$=14+B$ & & & & & & & \\
\hline $168-3$ & 53 & 34 & 6 & 13 & - & - & - \\
\hline $1601-5$ & 54 & 37 & 3 & 14 & - & 一 & - \\
\hline $1601-47$ & 51 & 39 & 2 & 10 & - & - & - \\
\hline 890 & 43 & 31 & 2 & 10 & - & - & - \\
\hline $\begin{array}{l}\text { Total } \\
=14+2 B\end{array}$ & 201 & 141 & 13 & 47 & - & - & - \\
\hline 386 & 72 & - & 2 & 69 & - & 1 & - \\
\hline $145-11$ & 48 & 3 & 4 & 41 & - & - & - \\
\hline $\begin{array}{l}\text { Total } \\
=14+3 B\end{array}$ & 120 & 3 & 6 & 110 & - & 1 & - \\
\hline $168-20$ & 49 & - & - & 17 & 1 & 31 & - \\
\hline $168-6$ & 50 & 1 & - & 22 & - & 27 & - \\
\hline $145-13$ & 45 & - & - & 20 & - & 25 & - \\
\hline $\begin{array}{l}\text { Total } \\
a=14+4 B\end{array}$ & 144 & 1 & - & 59 & 1 & 83 & - \\
\hline $145-10$ & 50 & - & - & - & - & 39 & 11 \\
\hline $145-23$ & 44 & - & 2 & - & - & 37 & 5 \\
\hline Total & 94 & - & 2 & - & - & 76 & 16 \\
\hline
\end{tabular}

(i) First pollen grain division

This stage was examined in $2 n=14+\mathrm{B}$ and $2 n=14+3 \mathrm{~B}$ plants. Similar to other grasses, the spindle in the first division is conspicuously off-centre, and the generative pole (close to the pollen grain wall) could be easily identified. But only few (15) cells were found in the critical anaphase stage, and the examination was necessarily qualitative. Pollen grains with $n=7+\mathrm{B}$ (produced by $2 n=14+\mathrm{B}$ and $2 n=14+3 \mathrm{~B}$ ) and pollen grains containing $n=7+2 \mathrm{~B}$ (produced by $2 n=14+3 \mathrm{~B}$ ) cells showed obvious non-disjunction of the $\mathrm{B}$ chromosomes, coupled with the movement of the daughter B's towards the generative pole (fig. 5). 


\section{(ii) Second pollen grain division}

Altogether 11 plants containing one to four B chromosomes were examined (table 5 ). In $2 n=14+\mathrm{B}$ plants more than half of the pollen grains did not contain supernumerary chromosomes $(n=7)$. But in the majority of the remaining pollen the generative nuclei contained $n=7+2 \mathrm{~B}$. In $2 n=14+2 \mathrm{~B}$ plants almost all pollen grains contained supernumeraries, and over 90 per cent. of their generative nuclei showed $n=7+2 \mathrm{~B}$. Also plants with $2 n=14+3 \mathrm{~B}$ showed a prevalence of generative nuclei with $n=7+2 \mathrm{~B}$ and $n=7+4 \mathrm{~B}$, and plants with $2 n=14+4 \mathrm{~B}$ produced mainly $n=7+4 \mathrm{~B}$ nuclei (fig. 6). However, in the latter plants we encountered an added complication: generative nuclei with $n=7+8 \mathrm{~B}$ occurred as well.

\section{Transmission tests}

The transmission of the B chromosomes to progeny was studied by means of crosses between plants containing one, two or three supernumeraries and plants lacking them. In each of these combinations the two reciprocal crosses were analysed. Altogether 260 progeny (in seedling stage) were scored. The results of these progeny tests are set up in table 6 .

TABLE 6

Transmission of supernumerary chromosomes in Aegilops speltoides. Frequency distribution of numbers of supernumerary chromosomes in progeny obtained from various crosses

\begin{tabular}{|c|c|c|c|c|c|c|c|c|c|c|c|}
\hline \multicolumn{3}{|c|}{ Cross combination } & $\begin{array}{l}\text { Number } \\
\text { of progeny }\end{array}$ & & & & & & & & \multirow{2}{*}{$\begin{array}{l}\text { Average } \\
\text { number of } \\
\text { B's in } \\
\text { progeny }\end{array}$} \\
\hline 우 & & 0 & examined & 14 & $4+B$ & $14+2 B$ & $14+3 B$ & $14+4 B$ & $14+5 B$ & $14+6 \mathrm{~B}$ & \\
\hline $\begin{array}{l}878 \\
(14)\end{array}$ & $\times$ & $\begin{array}{l}890 \\
(14+B)\end{array}$ & 40 & 25 & - & 15 & - & - & - & - & 0.38 \\
\hline $\begin{array}{l}890 \\
(14+B)\end{array}$ & $x$ & $\begin{array}{l}878 \\
(14)\end{array}$ & 18 & 15 & 3 & - & - & - & - & - & $0 \cdot 17$ \\
\hline $\begin{array}{l}878 \\
(14)\end{array}$ & $x$ & $\begin{array}{l}168-3 \\
(14+B)\end{array}$ & 18 & 10 & - & 8 & - & - & - & - & 0.44 \\
\hline $\begin{array}{l}168-3 \\
(14+B)\end{array}$ & $x$ & $\begin{array}{l}878 \\
(14)\end{array}$ & 21 & 17 & 4 & - & - & - & - & - & $0 \cdot 24$ \\
\hline $\begin{array}{l}777 \\
(14)\end{array}$ & $x$ & $\begin{array}{l}386 \\
(14+2 B)\end{array}$ & 62 & - & 2 & 59 & - & 1 & - & - & $2 \cdot 00$ \\
\hline $\begin{array}{l}386 \\
(14+2 B)\end{array}$ & $x$ & $\begin{array}{l}777 \\
(14)\end{array}$ & 72 & 1 & 69 & 2 & - & - & - & - & $1 \cdot 01$ \\
\hline $\begin{array}{l}878 \\
(14)\end{array}$ & $x$ & $\begin{array}{l}168-19 \\
(14+3 \mathrm{~B})\end{array}$ & 17 & - & - & 8 & 2 & 4 & - & 3 & $3 \cdot 29$ \\
\hline $\begin{array}{l}168-19 \\
(14+3 B)\end{array}$ & $\times$ & $\begin{array}{l}878 \\
(14)\end{array}$ & 12 & 1 & 7 & 4 & - & - & - & - & $1 \cdot 33$ \\
\hline
\end{tabular}

Total 260

(i) Reciprocal crosses between $2 \mathrm{n}=14+B$ and $2 \mathrm{n}=14$

Very conspicuous is the difference between the two reciprocal crosses. When the male parent carries the single B chromosome, $2 n=14+2 \mathrm{~B}$ progeny are encountered; when the female parent carries the single $B$, $2 n=14+\mathrm{B}$ progeny are formed. In addition, more than half of the 
progeny tested in both reciprocal crosses did not contain supernumerary chromosomes at all. These results corroborate the conclusions arrived at by the cytogenetic analysis of the parent plants. They show that $(a)$ the lagging of the single univalent observed in anaphase I cells brings about serious distortion in the expected $1: 1$ ratio of $n=7$ and $n=7+\mathrm{B}$ spores; (b) the accumulation mechanism in the $n=7+\mathrm{B}$ male gametophytes is usually effective and results in the formation of $2 n=14+2 \mathrm{~B}$ progeny; (c) no parallel accumulation mechanism operates on the female side. All progeny obtained from $\$ 2 n=14+\mathrm{B} \times \delta^{12} n=14$ had either a single $\mathrm{B}$ chromosome or did not contain supernumeraries at all.

\section{(ii) Reciprocal crosses between $2 \mathrm{n}=14+2 B$ and $2 \mathrm{n}=14$}

Here too the difference between the reciprocal crosses was apparent. When the male parent had two supernumeraries, almost all progeny (59 out of 62) contained two B's. When the female parent had two supernumeraries, almost all progeny (69 out of 72) carried only a single B chromosome (table 6).

These results demonstrate again the doubling of supernumeraries in the male gametophyte and testify that this accumulation process does not occur in the female gametophyte. Furthermore, it is obvious that the non-disjunction and directed migration in the male gametophyte is indeed a very regular process. It fails only in very few microspores. The presence of a single $2 n=14+4 \mathrm{~B}$ derivative is explicable in terms of repeated doubling: first by unipolar distribution of the two supernumeraries in meiosis, and second, by non-disjunction in the male gametophyte.

\section{(iii) Reciprocal crosses between $2 \mathrm{n}=14+3 B$ and $2 \mathrm{n}=14$}

When the male parent had three supernumeraries, most of its progeny carried even numbers of supernumeraries (two, four, six). When the female parent had three supernumeraries, its progeny contained only one or two supernumeraries (table 6). Also these results conform with the cytological analysis. Meiosis in $2 n=14+3 \mathrm{~B}$ plants results in spores containing one, two or even three supernumerary chromosomes. The fact that most progeny tested had two, four or six B's, reflects again the effectiveness of the accumulation in the male gametophyte. In contrast, the reciprocal cross indicates the lack of accumulation during the development of the female gametophyte.

\section{The EFFEGTS ON DEVELopMent AND FERTILITy}

Only a few tests have been performed on the effects of the supernumerary chromosomes on the growth and fertility of their carriers.

Our general impression was that under Jerusalem field conditions plants containing large (three to eight) number of B chromosomes, were stunted in growth. In fact, we could spot them in the field by their weak development.

Further data on retardation were provided by 30 sibs which were sown on the same day. In this sample the date of emergence of the first spike from the flag leaf was recorded. The emergence of the spike in plants containing four to six B's was 7-10 days later than in plants with a single B. 
There is an obvious trend of increasing pollen abortion with the increase of supernumerary chromosomes. Again, serious deterioration appears only when the number of supernumeraries is four or more. Thus plants containing one to three supernumeraries manifested normal formation of pollen (5-8 per cent. pollen abortion), while $2 n=14+4 \mathrm{~B}$ and $2 n=14+5 \mathrm{~B}$ formed 10-20 per cent. aborted pollen. Finally, plants with $2 n=14+6 \mathrm{~B}$ chromosomes were already semi-sterile on the male side and showed 40-50 per cent. pollen abortion. On the other hand, we did not find any obvious effect of the supernumerary chromosomes on seed fertility.

\section{Discussion}

\section{(i) Stability of supernumerary chromosomes in the various organs}

The available data indicate that the number of supernumerary chromosomes in the aerial parts of a given individual in Ae. speltoides is constant. In contrast, with the constant presence of B's in the tillers and stems, total elimination occurs in the roots. In other words, $\mathrm{B}$ chromosomes in $A e$. speltoides are maintained constantly in the germ line and apparently in the same number as originally transmitted to the zygote. In this pattern Ae. speltoides resembles several other " unstable B chromosome systems" in plants such as Sorghum purpuro-sericeum and Poa timoleontis (see review by John and Lewis, 1968).

Another evident feature is the loss of supernumeraries in meiosis-due to frequent lagging of univalents. This loss is considerable in $2 n=14+\mathrm{B}$ plants, and accounts for the distortion of the $1: 1$ ratio of $7: 7+B$ spores produced by such individuals. The distortion, in favour of B-less spores, is also recognisable in the progeny tests. Significantly, it is more severe on the female side (table 6).

\section{(ii) Accumulation mechanisms}

The observations on pollen grains show that at the end of the first division in the male gametophyte, supernumerary chromosomes in Ae. speltoides undergo non-disjunction and accumulate in the generative nucleus. When, at the end of meiosis, a B chromosome is included in the microspore, its number is regularly doubled in the ensuing generative nucleus. The effectiveness of this accumulation mechanism is borne out by the progeny tests. Thus these tests corroborated the cytological analysis and verified that, on the male side, accumulated B chromosomes were indeed effectively transmitted to progeny. The transmission tests also showed that there is no parallel accumulation mechanism on the female side.

All in all the accumulation system, in the male gametophyte, in $A e$. speltoides resembles closely the preferential non-disjunction described in Anthoxanthum (Östergren, 1947), Secale (Müntzing, 1954), Festuca (Bösemark, 1954) and Dactylis (Puteyevsky and Zohary, 1971). This type of accumulation seems to be characteristic of various grass genera belonging to the subfamily Pooideae.

In plants with high number of supernumerary chromosomes we encountered another complication. In some pollen grains we found generative nuclei with twice the number of supernumerary chromosomes expected from doubling at the gametophytic stage (i.e. $n=7+8 \mathrm{~B}$, see table 5). 
Such sporadic compound accumulation was indicated also by the progeny tests (table 6). This double accumulation can be explained on the basis of the sporadic unipolar distribution of supernumeraries encountered in meiosis.

\section{(iii) Selection against carriers}

If supernumerary chromosomes are indeed capable of parasite-like accumulation in critical cells involved in gamete formation, their increase has to be compensated for (Nur, 1969). Balance can be achieved by two main mechanisms: (a) Internal compensation, i.e. the occasional loss of $\mathrm{B}$ chromosomes, in the germ-line, during the development of the carrier. (b) External compensation, i.e. selection against the carriers. In Ae. speltoides somatic divisions in tillers and spikes were found to be surprisingly stable; supernumeraries are here effectively retained. Loss of B chromosomes was encountered only in meiosis-due to lagging of univalents. But the amount of meiotic loss is too small to balance the universal accumulation in the male gametophyte. It is almost negligible in plants carrying two to four B's (see table 3). Consequently selection against carriers (and particularly against plants containing several B's) is the main balancing element in Ae. speltoides. The available data on the effects of supernumeraries on the development and the relative fertility is admittedly fragmentary; but they indicate strongly that dosages of three to four supernumeraries already effect considerably the viability and fertility of the carriers. In other words, they do lower their adaptive value-at least under Jerusalem conditions.

It should also be noted that the effect of B's on pollen abortion is apparently sporophytically controlled. The progeny tests did not reveal any preferential abortion in the segregating pollen grains. Finally, one should stress the significance of the male semi-sterility observed in carriers which nevertheless manifested normal seed-set. Since accumulation in Ae. speltoides is in the male gametophyte, compensation by male sterility is twice as effective as compensation by female sterility.

\section{Summary}

1. The somatic stability of supernumerary chromosomes was studied in plants containing one to six B's. Carriers were found to maintain constant number of B's in their various tillers and spikes. In contrast, B chromosomes were, universally absent in roots.

2. Partial loss of supernumeraries (due to lagging) was noted in microsporocytes at the anaphase I stage of meiosis (particularly in plants containing a single B). Also occasional unipolar distribution of B's was detected at this stage.

3. Cytological examinations of pollen grains revealed accumulation of B's in the generative nucleus of the male gametophyte. This is brought about by directed non-disjunction of supernumeraries at the first pollen motosis.

4. Crosses were made between plants containing one to three B's and plants free of accessory chromosomes. The progeny tests showed that on the male side the accumulated B chromosomes are effectively transmitted to progeny. Reciprocal crosses revealed that no parallel accumulation occurs on the female side. 



\section{Explanations to Figures}

\section{Plate I}

FIG. 1.-Dividing hypocotyl cell in $2 n=14+6 \mathrm{~B}$ seedling (arrows point to supernumerary chromosomes).

FIGs. 2 and 3.-Metaphase $I$ in microsporocytes with $2 n=14+3 \mathrm{~B}$ and $2 n=14+4 \mathrm{~B}$.

FIG. 4.-Lagging of the B univalent at anaphase $I$ in $2 n=14+B$ plant.

Magnification of all figures $\times 6000$. 


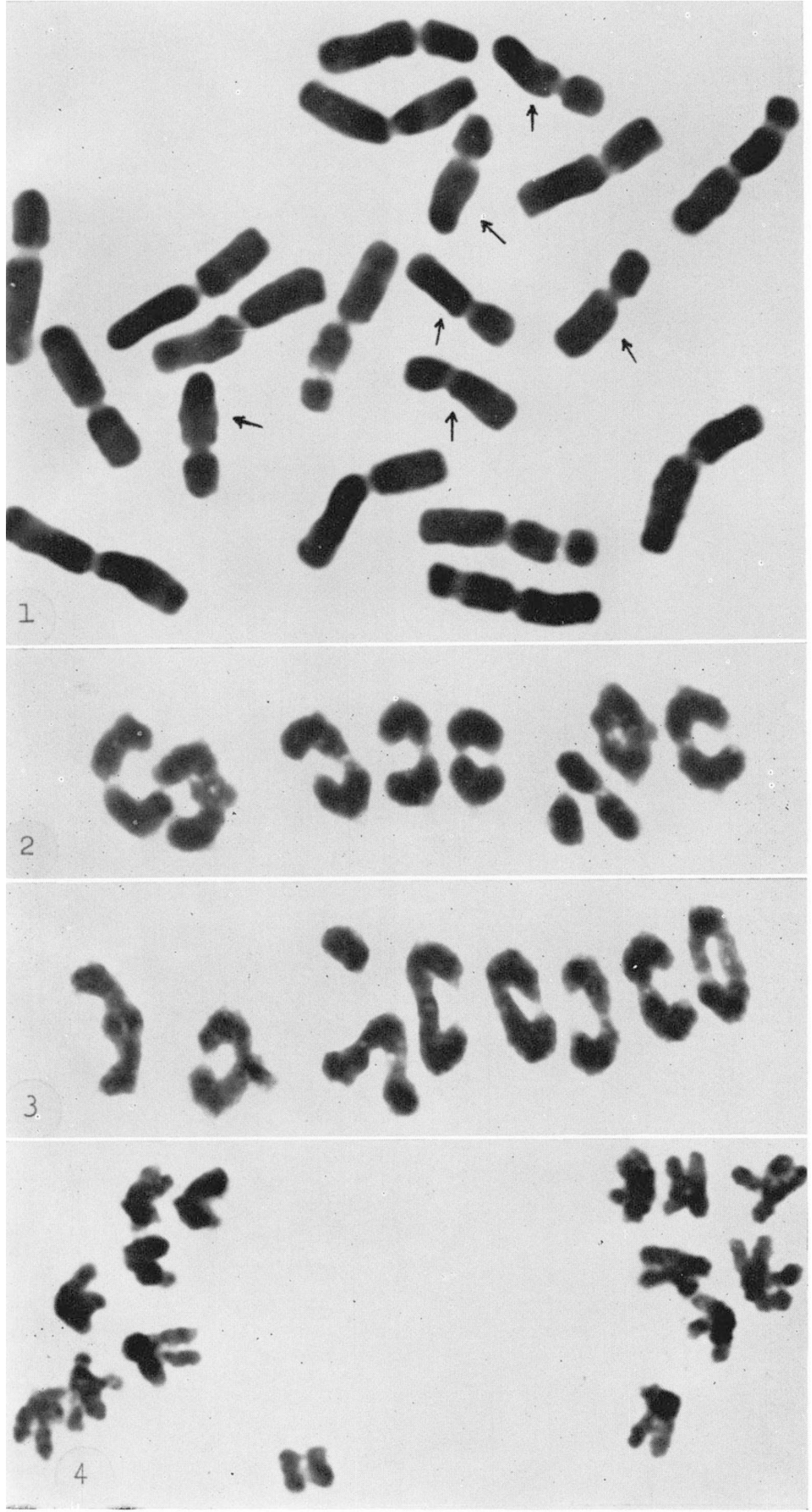




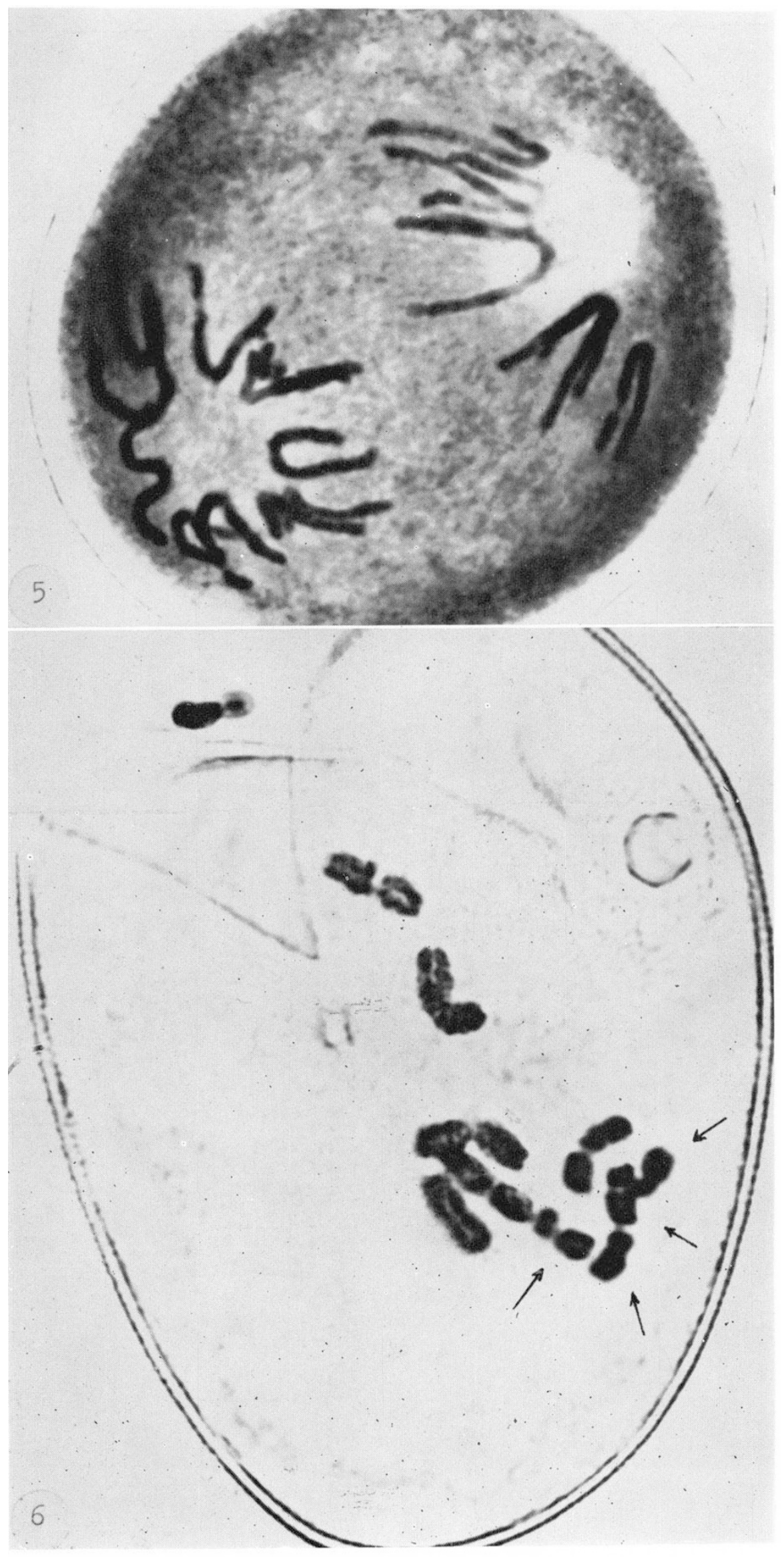




\section{Plate II}

FIG. 5.-Non-disjunction at anaphase in the first division of the pollen grain. The generative pole (left) contains $n=7+4 \mathrm{~B}$ chromosomes. The vegetative pole (right) has only $n=7$ chromosomes.

Fig. 6.-Metaphase in the second pollen grain division. This grain was produced by a $2 n=14+4 \mathrm{~B}$ plant. Its generative nucleus contains $n=7+4 \mathrm{~B}$ chromosomes (arrows point to the B's).

Magnification of all figures $\times 6000$. 

5. Stunted growth and progressive increase of pollen abortion was found in plants carrying numerous (three to six) supernumeraries.

6. The factors compensating for the parasite-like accumulation of B's in $A e$. speltoides are evaluated. The roles of $(a)$ internal loss and $(b)$ of selection against the carriers are discussed.

Acknowledgments.-Thanks are due to Dr G. Simchen and Mr Y. Zarchi for providing us with the initial plants. The authors are also indebted to Mrs Judith Dagan for her help in the crossing programme and in cytological preparations.

\section{REFERENCES}

BÖSEMARK, N. O. 1954. On accessory chromosomes in Festuca pratensis. II. Inheritance of the standard type of accessory chromosomes. Hereditas, 40, 425-437.

John, в., AND LEWIS, K. R. 1968. The chromosome complement. Protoplasmatologia, Band VIA, pp. 1-206. Springer-Verlag, Wien.

MüntZing, A. 1954. Cyto-genetics of accessory chromosomes (B-chromosomes). Caryologia, 6, suppl., 282-301.

NUR, U. 1969. Mitotic instability, leading to an accumulation of B chromosomes in Grasshoppers. Chromosoma, 27, 1-14.

ostergren, G. 1947. Heterochromatic B chromosomes in Anthoxanthum. Hereditas, 33, 261-269.

PUTEYEVSKY, E., AND ZOHARY, D. 1970. Behavior and transmission of supernumerary chromosomes in diploid Dactylis glomerata. Chromosoma (Berl.), 32, 135-141.

SIMCHEN, G., ZARCHI, Y., AND HILleL, J. 1971. Supernumerary chromosomes in the second outbreeding species of the wheat group. Chromosoma (Berl.), 33, 63-69.

sNow, R. 1963. Alcoholic Hydrochloric Acid-Carmin as a stain for chromosomes in squash preparations. Stain Tech., 38, 9-13.

zOHARY, D., AND IMBER, D. 1963. Genetic dimorphism in fruit type in Aegilops speltoides. Heredity, 18, 223-231. 